\title{
PERANCANGAN APLIKASI PEMINJAMAN BUKU PERPUSTAKAAN PADA SDN MEKARJAYA 11 DEPOK
}

\author{
Thasia Anjani ${ }^{1}, Z{ }^{\prime}$ imatun Niswati ${ }^{2}$, Intan Mutia $^{3}$ \\ Program Studi Informatika, Universitas Indraprasta PGRI \\ thasia.anjani15@gmail.com, zaimatunnis@gmail.com, as_syifaraa@yahoo.com
}

Submitted October 6, 2019; Revised June 27, 2020; Accepted July 26, 2020

\begin{abstract}
Abstrak
Aplikasi peminjaman buku pada SDN Mekarjaya 11 masih dilakukan secara manual, sehingga pencatatan peminjaman dan pengembalian tidak akurat. Tujuan dari penelitian ini adalah untuk mempermudah karyawan perpustakaan dalam mendata proses buku seperti peminjaman, pengembalian, denda serta laporan dari keseluruhan proses. Penulis menggunakan metode Research and Development, secara umum adalah pengembangan dan penelitian dalam bidang teknologi. Aplikasi peminjaman buku perpustakaan ini menggunakan bahasa Java juga mengunakan software Netbeans IDE, Xampp dan MySQL. Hasil dari perancangan ini adalah aplikasi perpustakaan SDN Mekarjaya 11 yang mempermudah kinerja karyawan dalam proses pendataan peminjaman buku.
\end{abstract}

Kata Kunci : Aplikasi, Perpustakaan, SDN

\begin{abstract}
The book lending application at SDN Mekarjaya 11 is still manually, so the recording of loans and repayments is inaccurate. The purpose of this study is to facilitate library employees in recording the book process such as borrowing, repayment, fines and reports of the whole process. The author uses the Research and Development method, in general is the development and research in the field of technology. This library application using the Java language also uses Netbeans IDE, Xampp and MySQL software. The result of this design is the library application of SDN Mekarjaya 11 which facilitates employee performance in the book lending data collection process.
\end{abstract}

Key Words : Application, Library, SDN

\section{PENDAHULUAN}

Disaat ini, teknologi sangatlah berperan penting pada kehidupan manusia. Teknologi seperti komputer jika dikelola dengan benar akan menjadi media informasi yang cepat, tepat dan akurat.

Suatu organisasi atau perusahaan membutuhkan pembaruan akan teknologi yang dipakainya. Pada dunia pendidikan, komputer menjadi hal penting untuk kemajuan karena memudahkan berbagai aktivitas seperti pengolahan data, pembuatan laporan serta penyimpanan data dan menghasilkan suatu informasi yang cepat, tepat dan akurat.

Perpustakaan adalah suatu unit kerja dari satu badan atau lembaga tertentu yang mengelola bahan-bahan pustaka, baik berupa buku-buku maupun berupa buku (non book material) yang diatur secara sistematis menurut aturan tertentu sehingga dapat digunakan sebagai sumber informasi oleh setiap pemakainya[2]. Secara definitif, perpustakaan sekolah adalah perpustakaan yang berada pada lembaga pendidikan sekolah, yang merupakan bagian integral dari sekolah yang bersangkutan, dan merupakan sumber belajar untuk mendukung tercapainya tujuan pendidikan sekolah yang bersangkutan[3]. Hal lazim dalam perpustakaan adalah tidak perlunya mengeluarkan biaya untuk meminjam buku yang diinginkan tapi harus tetap mengikuti prosedur yang sudah ditentukan. Pengunaan komputer untuk perpustakaan berguna untuk memudahkan aktivitas 
seperti penginputan data siswa, data peminjaman buku serta laporannya.

Sistem peminjaman buku pada SDN Mekarjaya 11 masih dilakukan seacara manual. Berdasarkan hal tersebut, maka penulis akan menggunakan komputer untuk mempermudahnya dan juga membuat menjadi suatu data informasi yang lebih akurat untuk peminjaman, pengembalian, denda serta laporan dari keseluruhan prosesnya.

Dalam pengembangan sistem informasi perpustakaan ini agar dapat mencapai sasaran dan tujuan yang diharapkan, maka penulis perlu membatasi masalah, yaitu, 1) aplikasi yang akan dihasilkan meliputi laporan data buku, data siswa, peminjaman buku dan pengembalian buku. 2) Aplikasi ini dibuat dengan menggunakan bahasa pemrograman Java dan menggunakan editor NetBeans. 3) Database yang digunakan dalam aplikasi ini adalah MySQL.

Adapun tujuan yang ingin dicapai dalam Perancangan Sistem Peminjaman Buku Pada Perpustakaan SDN Mekarjaya 11 adalah 1) Membuat sistem peminjaman dan pengembalian buku. 2) Meningkatkan efektifitas peminjaman dan pengembalian buku pada perpustakaan SDN Mekarjaya 11. 3) Mempermudah karyawan dalam menyimpan data, mengelola data dan membuat laporan dengan cepat, tepat dan akurat.

Manfaat dari perancangan aplikasi ini ialah agar kerja komputer pada lingkungan sekolah terpakai dan dalam pengerjaan masukan data dan juga laporannya menjadi lebih cepat, tepat dan akurat.

\section{METODE PENELITIAN}

Pada penelitian ini, penulis menggunakan metode Research and Development secara umum adalah pengembangan dan penelitian dalam bidang teknologi.
Metode penelitian dan pengembangan (Research and Development) adalah metode peneltian yang digunakan untuk menghasilkan produk tertentu dan menguji keefektifan produk tersebut. Produk yang dihasilkan juga dapat berupa modul, metode mengajar, media, sistem evaluasi [4].

\section{Metode Pengumpulan Data}

Metode pengumpulan data yang dilakukan oleh penulis untuk mendapatkan data data serta informasi untuk mendukung penyempurnaan hasil dari penelitian ini antara lain:

1. Studi Kepustakaan

Pengumpulan data dan informasi dilakukan dengan mempelajari buku-buku yang berhubungan dengan masalah yang sedang dibahas yang diperoleh dari perpustakaan Universitas, seperti mengutip buku-buku dan browsing melalu search engine di internet.

\section{Observasi}

Observasi adalah pengamatan langsung terhadap tingkah laku peserta didik didalam situasi sosial, dan merupakan bantuan yang sangat penting sebagai suatu alat evaluasi[5]. Penulis mempelajari dan mengamati perpustakaan yang terdapat di Sekolah Dasar Negeri Mekarjaya 11 Depok.

3. Wawancara

Wawancara merupakan suatu teknik pengumpulan data yang dilakukan dengan cara tanya jawab antara penanya dengan penjwab. Penulis melakukan wawancara langsung kepada petugas tata usaha, Bapak Abdul Adjis untuk mendapatkan data informasi yang dibutuhkan.

Dari hasil wawancara, terdapat berbagai masalah dan kendala yang dialami para petugas perpustakaan, diantaranya penyimpanan data peminjam yang masih dilakukan secara manual, data-data yang tidak tersimpan dengan baik membuat petugas kesulitan dalam pembuatan laporannya. 


\section{Langkah-langkah Pengembangan}

Dalam pengembangan sistem aplikasi perpustakaan SDN Mekarjaya 11 Depok, penulis menggunakan model waterfall.

Model waterfall adalah proses pengembangan perangkatt lunak tradisional yang umum digunakan dalam proyek-proyek perangkat lunak pembangunan. Ini adalah model sekuensial, sehingga penyelesaian satu set kegiatan menyebabkan dimulainya aktivitas berikutnya[6].

Pada proses waterfall ditunjukkan metode pengembangan dimana pengembang aplikasi diharuskan mengikuti langkahlangkah sebagai berikut :

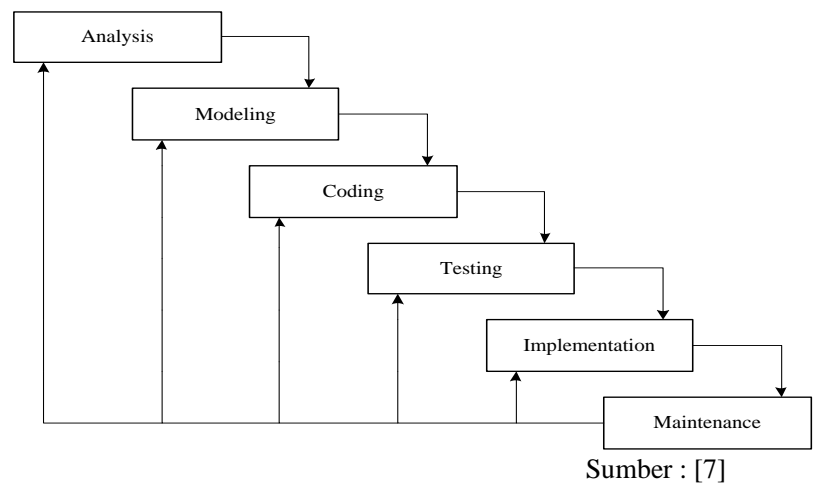

Gambar 1. Model Waterfall

Berikut ini adalah penjelasan dari tahapantahapan yang terdapat dalam metode waterfall, yaitu :

1. Analysis, merupakan tahap dimana rekayasa perangkat lunak menganalisa hal- hal yang diperlukan dalam pelaksanaan.

2. Modeling, membantu dalam menentukan perangkat keras (hardware), perangkat lunak (software) dan sistem persyaratan serta membantu dalam mendefinisikan arsitektur sistem secara keseluruhan.

3. Coding, Merupakan tahap penerjemahan data pemecah masalah yang telah dirancang kedalam pemograman komputer yang telah ditentukan.
4. Testing, Merupakan tahapan pengujian terhadap perangkat lunak yang telah selesai dibuat untuk menemukan kesalahan-kesalahan atau kekurangan yang terdapat di dalam sistem.

5. Implementation, tahap dimana semua elemen dan aktivitas sistem disatukan. Adapun yang dilakukan oleh penelitian dalam tahap ini adalah menyiapkan fasilitas fisik, menyiapkan pemakai (user) dan melakukan simulasi.

6. Maintenance, yaitu tahap akhir dimana perangkat lunak sudah selesai dan mengalami perubahan atau penambahan sesuai dengan permintaan.

\section{HASIL DAN PEMBAHASAN}

Penulis membuat aplikasi peminjaman buku perpustakaan menggunakan Java, Netbeans IDE dimana Java merupakan bahasa pemrograman berorientasi objek yang merupakan paradigma pemrograman masa depan, sedangkan Netbeasn adalah aplikasi Integrated Development Enviroment(IDE) berbasiskan java dari Sun Microsystem yang berjalan diatas swing. Proyek ini berdiri pada tahun 2000 dan telah menghasilkan 2 produk, yaitu Netbeans IDE dan Netbeans platform[8],[9],[10]. Aplikasi ini juga menggunakan basis data $M y S Q L$, yaitu sebuah perangkat lunak sistem manajemen basis data $S Q L$ atau yang dikenal dengan DBMS(Database Management System)[11]. MySQL ini bermanfaat untuk mengelola data dengan perangkat lunak ini bermanfaat untuk mengelola data yang sangat cepat dan fleksibel[12]. Penulis memberikan akses login, data siswa, buku, peminjaman dan pengembaliannya serta laporan pada masing-masing data. 
1. Tampilan Login

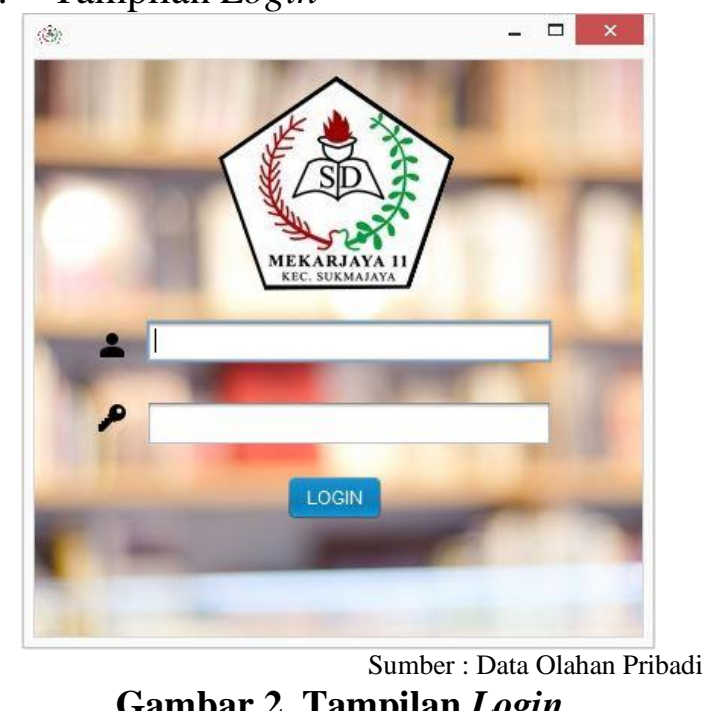

Tampilan login ini dipergunakan untuk masuk ke tampilan menu utama. Tampilan ini berisikan user dan password untuk petugas yang sudah terdaftar.

2. Tampilan Menu Utama

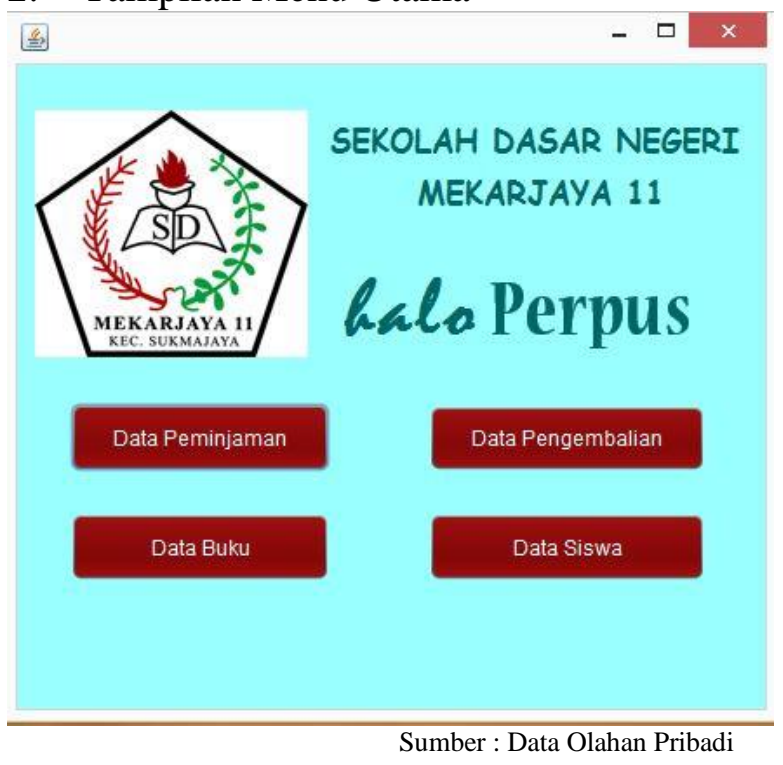

Gambar 3. Tampilan Menu Utama

Tampilan menu utama ini terdapat beberapa pilihan menu yang akan menampilkan form-form masukkan dan diantaranya adalah data siswa, data buku, data peminjaman dan data pengembalian.
3. Tampilan Form Data Siswa

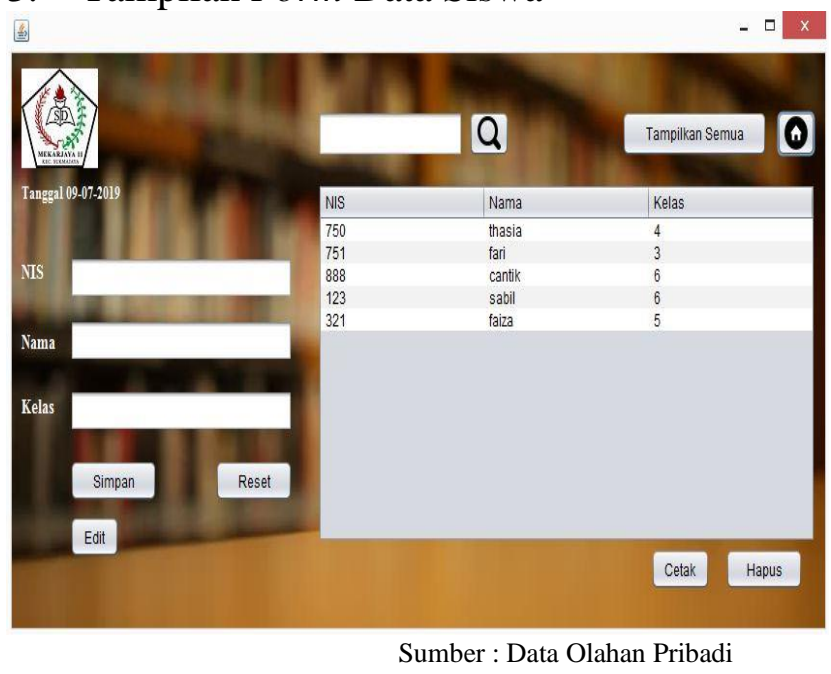

\section{Gambar 4. Tampilan Form Data Siswa}

Tampilan form data siswa ini untuk dapat melakukan penambahan data siswa, penghapusan data siswa, pengubahan atau edit pada data siswa dan pencetakan laporan data siswa. tampilan ini hanya dapat dilakukan oleh petugas.

\section{Tampilan Form Data Buku}

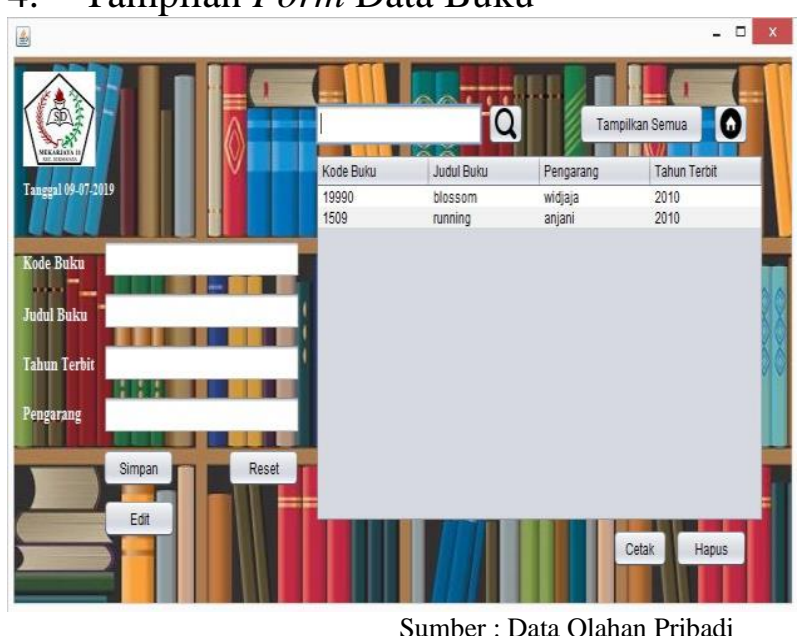

\section{Gambar 5. Tampilan Form Data Buku}

Tampilan form data buku ini untuk dapat melakukan penambahan, penghapusan, pengubahan dan pencetakan data buku. Tampilan ini hanya dapat dilakukan oleh petugas. 
5. Tampilan Form Data Peminjaman

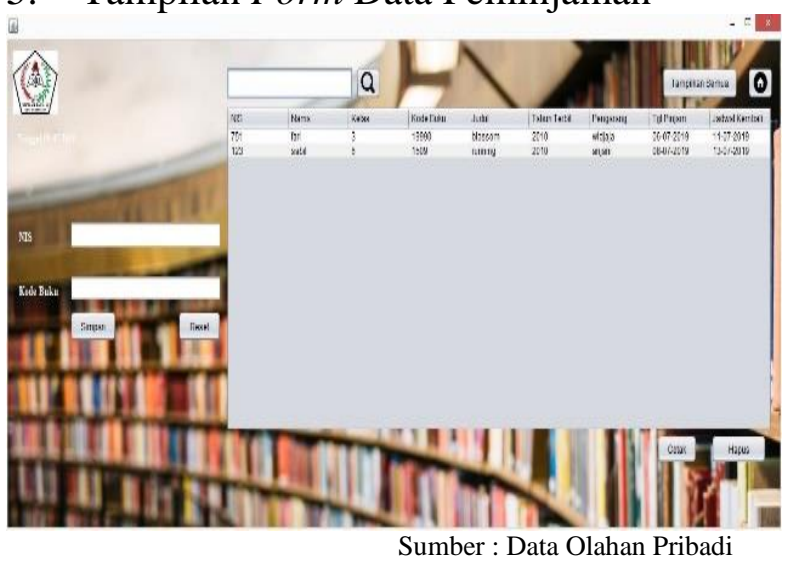

Gambar 6. Tampilan Form Data

Peminjaman

Tampilan form data peminjaman dilakukan saatt siswa melakukan peminjaman dengan mebawa lembar peminjaman. petugas dapat melakukan penambahan data peminjaman, penghapusan data peminjaman dan pencetakan laporan data peminjaman. Form peminjaman ini hanya bisa dilakukan oleh petugas.

6. Tampilan Form Data Pengembalian

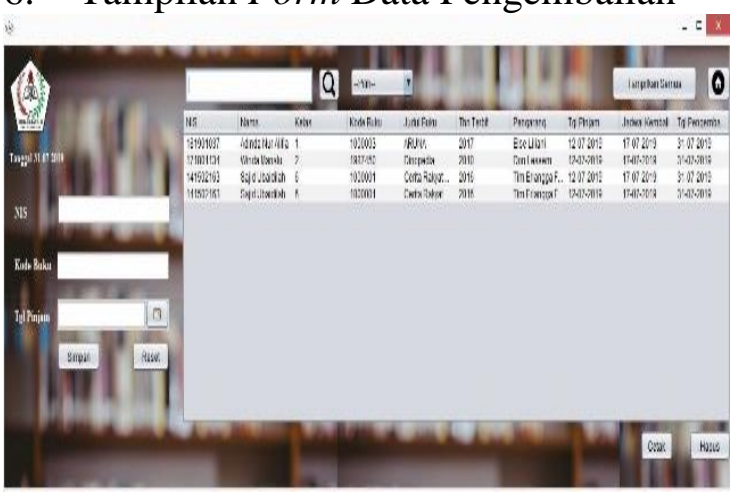

Gambar 7. Tampilan Form Data Pengembalian

Rancangan form data pengembalian ini petugas dapat melakukan penambahan, penghapusan dan pencetakan data pengembalian. Form pinjaman ini hanya bisa dilakukan oleh petugas.
7. Tampilan Laporan Data Siswa
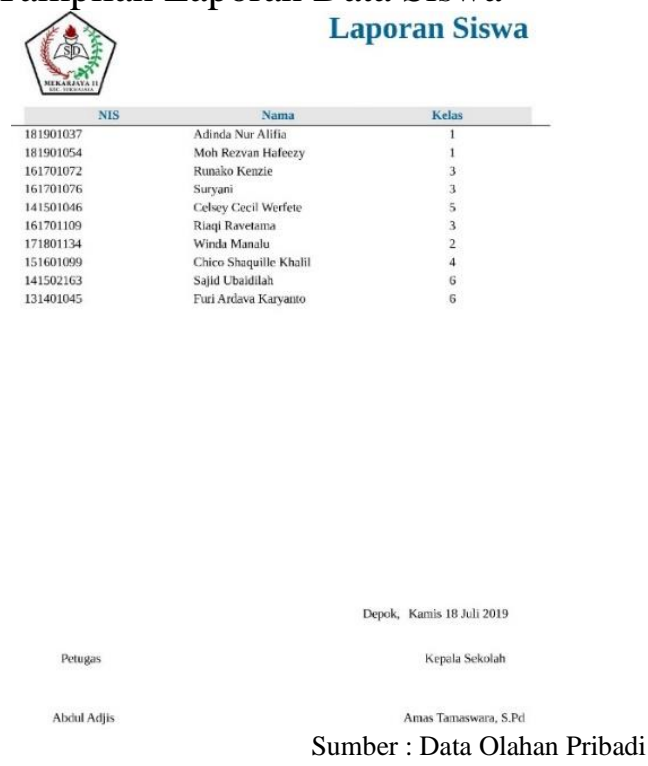

Gambar 8. Tampilan Laporan Data Siswa

Tampilan laporan data siswa ini berisi data-data yang ada pada tabel data siswa. Laporan ini muncul ketika petugas mengklik tombol cetak pada tampilan data siswa

8. Tampilan Laporan Data Buku
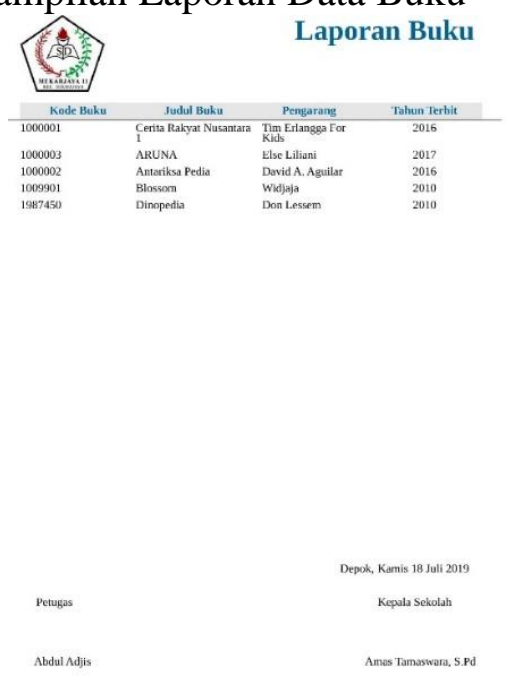

Gambar 9. Tampilan Laporan Data Buku

Tampilan laporan data buku ini berisi datadata yang ada pada tabel data buku. Laporan ini muncul ketika petugas mengklik tombol cetak pada tampilan data buku. 
9. Tampilan Laporan Data Peminjaman
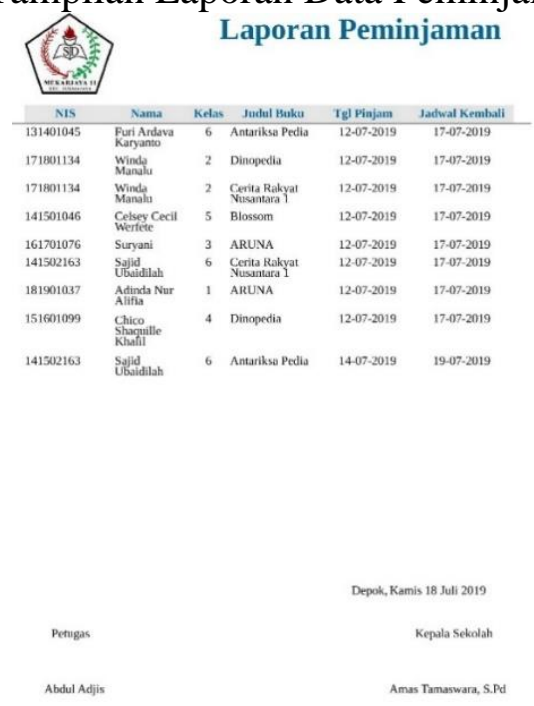

Sumber : Data Olahan Pribadi

Gambar 10. Tampilan Laporan Data

\section{Peminjaman}

Tampilan laporan data peminjaman ini berisi beberapa data yang ada pada tabel data peminjaman. Laporan ini muncul ketika petugas mengklik tombol cetak pada tampilan data peminjaman.

10. Tampilan Laporan Data Pengembalian
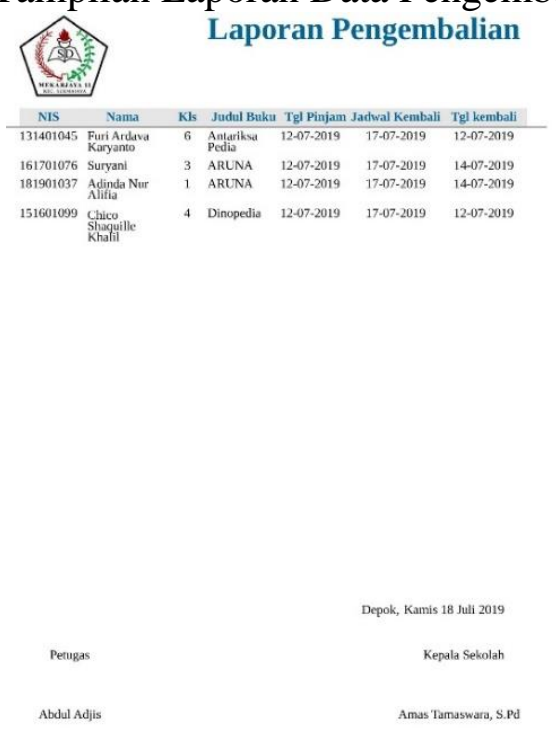

Sumber : Data Olahan Pribadi

Gambar 11. Tampilan Laporan Data Pengembalian

Tampilan laporan data pengembalian ini berisi beberapa data yang ada pada tabel data pengembalian. Laporan ini muncul ketika petugas mengklik tombol cetak pada tampilan data pengembalian.

\section{SIMPULAN}

Berdasarkan penelitian dan analisis yang dilakukan, penulis dapat menarik simpulan untuk memecahkan masalah yang dihadapi oleh Perpustakaan SDN Mekarjaya 11 Depok dalam meningkatkan kinerja pelayanannya, yaitu:

1. Proses peminjaman dan pengembalian buku menjadi lebih efektif dan efsien karena sudah terkomputerisasi dan tidak menggunakan input manual.

2. Aplikasi ini dapat membantu proses pengelolaan penyimpanan data.

3. Pembuatan laporan menjadi lebih efektif dan efisien.

\section{DAFTAR PUSTAKA}

[1] M. Nazir, Metode Penelitian. Bogor: Ghalia Indonesia, 2014.

[2] I. Bafadal, Pengelolaan Perpustakaan Sekolah. Jakarta: Bumi Aksara, 2015.

[3] Hartono, Manajemen Perpustakaan Sekolah: Menuju Perpustakaan Modern dan Profesional. Yogyakarta: Ar-Ruzz Media, 2016.

[4] Sugiyono, Metode Penelitian Pendidikan Pendekatan Kuantitatif, Kualitatif, dan $R$ \& D. Bandung: Alfabeta, 2009.

[5] S. Mania, "Observasi Sebagai Alat Evaluasi Dalam Dunia Pendidikan Dan Pengajaran," Lentera Pendidik. J. Ilmu Tarb. dan Kegur., vol. 11, no. 2, pp. 220-233, 2008.

[6] F. Imam and S. Azhari, "Proses Pemodelan Software Dengan Metode Waterfall Dan Extreme Programming: Studi," J. Speed, vol. 4, no. 3, 2012.

[7] S. Agarwal, "Waterfall Model," c\#Corner. [Online]. Tersedia: https://www.csharpcorner.com/UploadFile/ae6b35 
/waterfall-model-in-softwaretesting/. [Accessed: 01-Sep-2019].

[8] A. R. Putera and M. Ibrahim, "Rancang Bangun Sistem Informasi Peminjaman dan Pengembalian Buku Perpustakaan SMP Negeri 1 Madiun," DOUBLECLICK J. Comput. Inf. Technol., vol. 1, no. 2, p. 57, 2018.

[9] A. Afriansyah, "POLITEKNIK SEKAYU MENGGUNAKAN PEMROGRAMAN JAVA, vol. 3, no. 2, pp. 53-61, 2015.
[10] R. AS and M. Shalahuddin, Rekayasa Perangkat Lunak Terstruktur Dan Berorientasi Objek. Bandung: INFORMATIKA, 2015.

[11] E. Setyawan and B. E. Purnama, "Pembangunan Sistem Informasi Perpustakaan Sekolah Dasar Negeri ( SDN ) Pacitan," J. Sentra Penelit. Eng. dan Edukasi, vol. 4, no. 3, pp. 20-24, 2012.

[12] A. Kadir, Dasar Aplikasi Database MySQL-Delphi. Yogyakarta: Andi, 2010. 